eikon journal on semiotics and culture

\title{
Mujie Li
}

\section{Machine}

\section{Languages}

\section{as \\ Media \\ Infrastructures}

With the context that digital and computational technologies operate symbols in processing information and communication, it is necessary to look into machine languages and think about their relationship to us. This paper argues that through affording communications between machines and humans, machine languages become structures of media. To construct this argument, the paper will first define machine language as a pragmatic way of operating symbols and clarify its mathematical, mechanical and socially interactive levels. Based on Roman Jakobson's linguistic theory, the paper outlines that the metalingual and the poetic functions are the two major functions of machine languages. Because a diagrammatic thought deriving from Charles Sanders Peirce and Gilles Deleuze's linguistic thoughts is helpful to understand the functions of language at different levels of machine languages, the paper then moves on to explain how the functions of the metalanguage and poetics work in a diagrammatic thought process of machine language.

To examine the argument, the paper selects a virtual city model of the Alphatown as a case study, at first analyses how the metalanguage functions via the mediums of listing and navigation in the Alphatown, then looks at how the affects of boredom, being lost and strangeness arise from the media infrastructures based upon metalanguage, and analyses where the poetic function lies in the transmission of affects and how the sensual and the material aspects of machine languages emerge thus functioning as poetic. With analyzing the metalingual and poetic functions in a diagrammatic 
thought of machine languages, different levels of machine languages can be considered as media structures, while media structures manifest themselves as material and processual in the meantime.

\section{Keywords}

Machine languages, Media, Structures.

\section{Introduction to the Alphatown}

The Alphatown project ${ }^{1}$ is an excess product of the Douban online community that was launched in 2010. By excess I refer to a kind of energy of active users overflowing from Douban to Alphatown, hence the Alphatown was built and configured in this background. Regarding the construction of the Alphatown, its basic structure is based on listing, following the structure of the Douban website; for example, the categories (books, films, music, etc.) of Douban are composed of lists of data objects, such as book cover images, book names, contents, comments and reading notes, and users are able to add information on any of these components and make further lists of what has been read, what is being read, and what is going to be read, etc.; while the Alphatown is arranged in a list of urban blocks, in which lists of streets, shops and apartments are laid out (See Figures 1.1, 1.3 and 1.4).

At its first stage, the beta test of the Alphatown only opened to Douban-registered users, allowing active users to generate qualities of virtual streets, apartments and shops by data; for example, users are able to name streets as well as add images and texts to shops and apartments; these names, texts and images formulate the qualities of streets, apartments and shops. Only permitting the elites from Douban to access it limits yet also constructs the style of the Alphatown, and it also becomes the first and main cause that limits further interactions by the general public. Hence, the motivation for production runs out, leading to the gradual obsolescence of the virtual city.
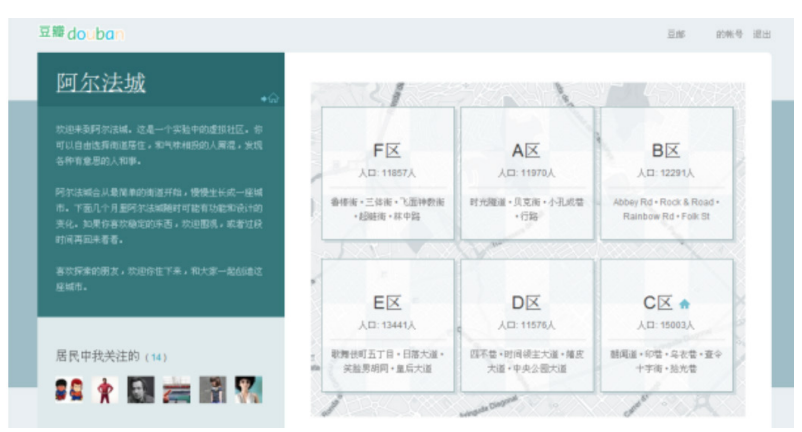

Figure 1.1

The original block layout of Alphatown. Screenshot from Alphatown web page, alphatown.com.

With the Alphatown opening to the general public, whereby the game designer intended to bring in more users to play the game, Alphatown showed a change in the map pattern at the interface from blocks to a honeycomb shape (See Figure 1.2, below). This new map allows more users to "live in" and gives a greater capacity for interactions in the game, hence navigation bars are introduced into the infrastructures of streets, shops and apartments, allowing users to mobilise themselves to construct structures of the virtual city. However, these navigational functions in a way counteract the interactions from users as users

1 The Alphatown website was closed down on May 20, 2015 due to the loss of traffic and active users. The original website address is http://alphatown.com/; and see Douban, accessed on April 4, 2016, http://www.douban.com. 
are easily lost in the navigation, while also the overall design of the virtual city does not generate more interactive experiences by users, especially when the game designer found that the change of the map pattern did not work in bringing in more active users.

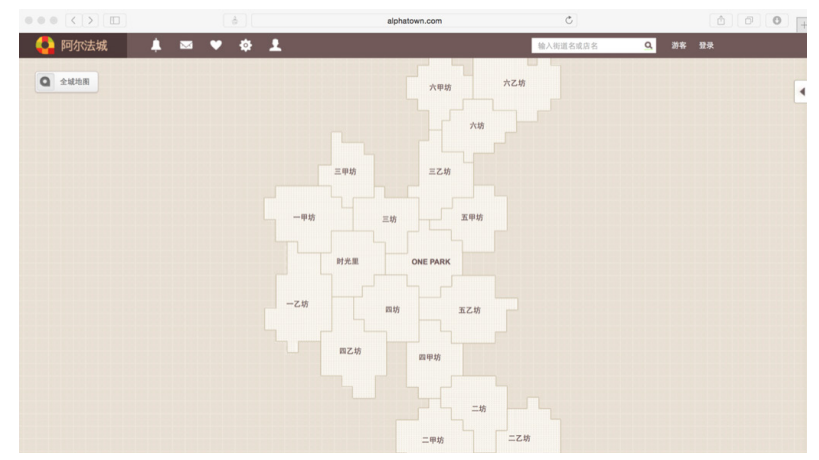

Figure 1.2

Overview of the graphic map of Alphatown. Screenshot from Alphatown web page, alphatown.com.

Thus, they stopped fixing the bugs in the game and let the virtual city grow under the force of users. This became the second cause for the obsolescence of the Alphatown. It leads to the fact that users began to communicate about the affects of being lost as well as the strangeness and boredom within the structure of the virtual city, such as using talking boards in the neighbourhoods to exchange information on the rules of play or inventing new rules of play. Hereby, the information these mediums carry is not about what the virtual city model intends to produce according to the game rules, it rather becomes noise redundant to the game production process, but is then turned into another kind of information for users' playing and inventing new "rules" of communicating and visualizing effects within the same structures.

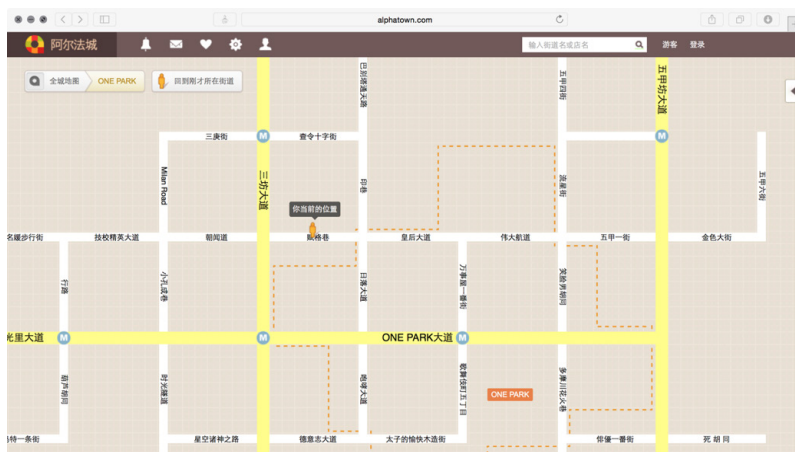

Figure 1.3

Street, metro station and navigation button list out mobility that eludes user operations. Screenshot from Alphatown web page, alphatown.com.

Although later, when the game designer recognised the obsolescence of the virtual city, they introduced a metro transportation network, added amongst the nodes of the streets, in order to mobilize users' activities and generate more traffic. This structure failed to do so in that it functioned as a navigation tool that again made users confused and isolated users' activities, hence it accelerated the ob- solescence of the virtual city. Amongst the sense of isolation, users began to exchange information for communicating new rules of play: sourcing from the affects of being lost, strangeness and boredom, users in the Alphatown intently left a massive quantity of messages on the talking boards, waiting for the automatic erasing mechanism of the system to produce the empty form of the street, hence generating the affect of obsolescence through users' experiences.

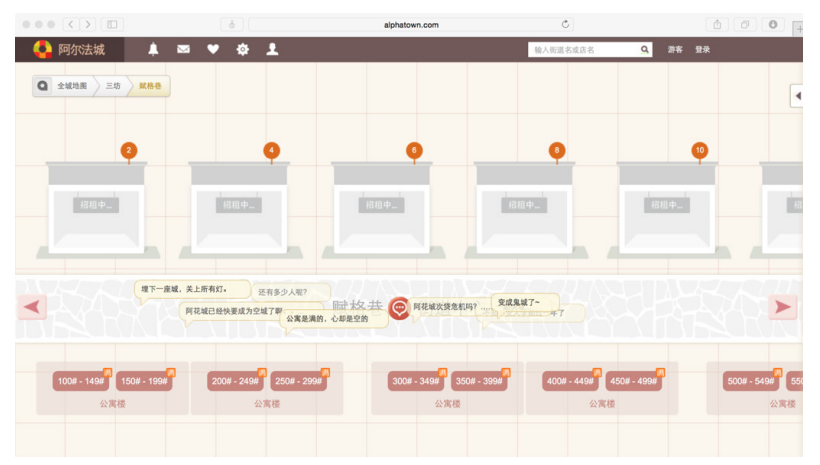

Figure 1.4

The attribute of boredom is structured and expressed in shops for rent, apartment buildings, message box of residents on the street. Screenshot from Alphatown web page, alphatown.com.

\section{The Media Infrastructures of the Alphatown}

Alphatown as a case study allows us to think whether a building of data structures can be seen as structures and forms of media and mediations, allowing forces to circulate within and among this. Machine languages provide a way of understanding themselves as structures of media through affording communications between human and machines. By machine language I mean a pragmatic way of operating symbols within machines. In the context of the Alphatown, the construction of data structures at the interface is a form of machine language; data structures' construction communicates user input and the design of computational technologies. However, this socially interactive level of machine languages belongs to only a part of machine languages. This paper aims to clarify and analyze machine languages on both mathematical and mechanical as well as socially interactive levels.

In order to analyze how machine languages become structures of media, I first propose that there are two major functions of machine languages, drawing upon Roman Jakobson's linguistic theory: the metalingual and poetic functions. Because a diagrammatic thought deriving from Charles Sanders Peirce and Gilles Deleuze's linguistic thoughts is helpful to understand the functions of language at different levels of machine languages, this paper will move on to explain how the functions of the metalanguage and poetics work in a diagrammatic thought process of machine language. To examine the argument, the text then puts the theoretical framework into the case study of the Alphatown, first analyzing how the metalanguage functions via the mediums of listing and navigation in the Alphatown, then moving on to look at how the affects arise from the media infrastructures based upon metalanguage and to analyze where the poetic function lies in the transmission of affects and how the sensual 
and the material aspects of machine languages emerge, thus functioning as poetic. Through analyzing the metalingual and poetic functions in a diagrammatic thought of machine languages, different levels of machine languages can be considered as media structures, while media structures manifest themselves as material and processual in the meantime.

\section{Machine languages as structures of media}

The argument this paper would like to construct is that machine languages become structures of media in distributing forces while also making media material and processual. To develop this argument, a definition must first be made of a machine language: language is a system of symbols as a method of both verbal and non-verbal communications, while machines in digital cultures refer more to digital and computational machines. Because the execution of code is the mechanism of digital and computational machines, it can be considered as a way of operating symbols. Hence, the operations of symbols can also be seen as a method of communication both between machines themselves and between machines and humans. There are different layers of machine languages. On the mathematical and mechanical level, machine language is a set of codes consisting of instructions that are executed directly by the computer's processing unit, like when a machine language works at the hardware dimension. Regarding the software dimension, programming languages are designed to communicate instructions to machines, specifically, assembly language corresponds to a particular architecture of the computer, and interpreted language in programming implements command subroutines already compiled into machine code. Therefore, machine languages here not only denote the execution of code on a hardware dimension, they also cover the software dimension in the execution of code. Following this, I propose they also work at the level of social interactions of code. Because the operation of software relies on users' feedback as input, it also works under the social circumstances in which particular operational functions of software by users directly cause the command and implementation of the programme; for example, the upgrade of a software is determined by its exposure to bugs in social use. Such a formulation on the definition of machine language suggests that the execution of code is inseparable from the transmission of a message in communications and, henceforth, machine languages become essential to understand media and forms of mediations.

Then the question to be asked is how machine languages become structures of media. To approach this question, we first need to understand the structuralization of machine languages in relation to linguistic theories of structuralism. This understanding requires us to know the changes which language is undergoing in the context of digital and computational machines. From linguistic theories of structuralism, the study of signs is composed of the signified and the signifier, as developed by Ferdinand de Saussure (1959), which corresponds to thought and sound. In machine languages, however, thought and sound are detached from humans and internalized into machines. Thought becomes processes of reasoning while sound becomes a series of actions effectuated by operations. Code in the middle of reasoning and action on the one hand ex- ecutes processes of reasoning; on the other hand, it simulates actions in the implementation. Such an elemental analogue between signs of natural languages and those of machine languages illustrates a condition of applying linguistic theories of structuralism to machine languages. Furthermore, the work of Roman Jakobson combines the functions of languages into the communication model of code and message (Jakobson, 1960; Geoghegan, 2011). This development in linguistic theories in turn offers a view of looking at machine languages based upon code and message, suggesting there is the potential of machine languages being the structures of media and forms of mediations.

Within this context of machine languages, this paper proposes to use Jakobson's linguistic formula as an entry point to analyze and think about how machine languages become structures of media. The formula (Jakobson, 1960) states that the metalingual and the poetic functions are two major functions of verbal communication among the other four functions: referential, emotive, conative and phatic. The metalingual function addresses the code itself in verbal communication, while the poetic function addresses the message in verbal communication. Machine languages internalize code into the execution process, and this execution of code is not only manifested in informing about commands or engagements, but also in effectuating specific and immanent acts. Such a process reflects the metalingual and poetic functions of machine languages, because either commands or further acts work within the operation of code itself, while code becomes communicative in informing commands or engagements and effectuating acts.

To further illustrate the functions of metalanguage and poetics in machine languages, the diagrammatic thoughts of Peirce and Gilles Deleuze respectively give some outlines in relation to different levels of machine languages. To reiterate the analysis above, machine languages can be seen as a compound of different levels, the mathematical and mechanical level including the function of code at the hardware and software dimensions, and the socially interactive level based on code and message. Regarding today's digital cultures, what are manifest as phenomena of machine languages are those social activities involving the operations of software. In relation to the case of the Alphatown to be discussed in the following part of this paper, its data structure among the website interface is the object conjuncting between the design iterations by the game designer and the inputs and feedback from the users. Before investigating the metalingual and poetic functions of the building of the data structures of the Alphatown, a diagrammatic thought is helpful for us to understand the major functions of machine languages in an overall sense of different levels of machine languages.

Speaking of the mathematical level of machine languages, Peirce's diagrammatic thought explains the way of understanding how such a level of machine language works in the context of the operations of signs. For Peirce, thought process is formalized by speculation through a process of reasoning, which is conceived as a diagrammatism, the process of thought's self-control (Vellodi, 2014). This diagrammatic thought is a system of signs that are aligned with their practical effects on the world. Such a practical semiotics consists of dynamic elements constituting semiotics as a process: objects, signs and interpretants. The 
sign is determined by the representation of objects, and in turn determines an effect, its interpretant. This principle of diagrammatic thought can be considered as the operation process of machine languages, where the machine simulates an object by operating signs, hence effectuating acts through execution and implementation. In this process of diagrammatic thought, thought deals with logical truth in a way of speculative reasoning, that is, "the role of the diagram is as generator of the laws that permit the determination of the future with increasingly greater clarity, to aid the movement of logic from the vague (particulars) to the definite (general), the movement of thought's 'self-controlling' towards its ultimate destination: truth" (Vellodi, 2014). Therefore, such a process functions as metalingual, addressing code itself.

However, the level of social interactions of code is also included in machine languages, and it opens up space for machine language to engage with the outside of machine reasoning and in turn actualizes machine languages as material and sensual. Deleuze's construction on diagrammatic thought gives a demonstration of this. Based on Peirce's pragmatic semiotics, Deleuze develops diagrammatic thought in constructing new reality as modes of being of material existence, which is in contrast to Peirce's logical possibility. The theory of signs thus orients towards their practical bearings on the production of life, it is an asignifying semiotics stressing semiotic materials that cannot be reduced to linguistic forms. The diagram hence is a pure difference in itself, and signs are passages of deterritorialisation and reterritorialisation, "they mark a certain threshold crossed in the course of these movements" (Deleuze \& Guattari, 2005). Deleuze's diagram acts as an "abstract machine", a pure matter function with no form or substance of its own. "'Abstraction' designates rather the intensive (differential, prior to the distinction interior/exterior), 'machinic' (immanently and non-deterministically functional) and genetic (immanently creative/constructive) plane of forces that 'precedes' formalization and from which 'a real that is yet to come, a new type of reality' emerges" (Vellodi, 2014). In relation to machine languages, signs operated by codes directly trigger the implementation of acts and internalize further exterior actions into renewed coding and commanding, such a deterritorialisation and reterritorialisation combines codes with attributes of real things to construct reality. This process can be considered as the functioning of the poetics focusing on message itself, message in this context referring more to a form of communication generated between machine and human.

From the functions of machine languages focusing on code and message, machine languages can be considered as the structures of media. In addition, the diagrammatic thought process of machine languages draws on reasoning as well as the opening of signs; it indicates that the structures of media are constantly shifting in differentiating relations, which I will explain in the following parts. In relation to the case of the Alphatown, the machine language is the building of data structures. The following parts will analyze how the metalingual and poetic functions work in this virtual city model, and this process in turn demonstrates that media are processual and material.
This paper provides a reading of the Alphatown by analyzing the metalingual and poetic functions of the data structure construction. In the initial stage of model configuration of the Alphatown, the list as a basic way of data organisation accumulates a certain amount of data together with the navigation bar. For example, the patterns of street, shops and apartments in the virtual city are built upon the logic of lists. With the aid of the navigation bar, users are able to add data to selected streets, shops and/ or apartments. Lists map out the patterns of the virtual city, and especially when the Alphatown project was in its beta test, the structure of the virtual city was still based on lists of the names of streets, and the visual representation of the virtual city was lists of links rather than a honeycomb shape graphic. Therefore, list is one of the conditions determining the structures of the virtual city. In the meantime, navigation becomes another condition causing the structuralisation of the Alphatown. Navigation gives an overall grasp of the different layers of the virtual city, and it is a way of distributing data among an existing structure, thus it formulates another layer of structure within. According to Jakobson (1960), the metalingual function focuses on the code itself in language, that is to say, the addresser and the addressee pay attention to the same code when transmitting a message. In the initial stage of the Alphatown, the game designer as the addresser intended to build the data structure on the basis of users' interest, while the users as the addressee did so through the mediations of list and navigation. List and navigation here as ways of coding no longer formulate significations, but programme certain instructions, in a sense. ${ }^{2}$

Here it is necessary to distinguish that listing and navigation, as ways of coding, perform different functions at the initial stage of data accumulation and the later stage of transmitting affects in the Alphatown, and these functions directly differentiate the functions of the metalanguage and the poetics in the data structures of the Alphatown. As stated above, list and navigation programme certain instructions as ways of coding between the architecture designed by the game designer and modified by the user. This belongs to a metalingual function because the addresser (game designer) and the addressee (the user) mediate lists and navigation tools to communication instructions. This metalingual function offers a foundation for data accumulation and paves the way for transmitting further affects that perform the poetic function. Yet, at the later stage of transmitting the affects of boredom, being lost and strangeness, listing and navigation serve as the communication of messages: this on the one hand generates a sense of isolation in playing the game, triggering a form of inactivity; on the other hand, these inactivity produces excess energies, hence listing and navigation encode the affects in the data structures of the Alphatown.

\footnotetext{
2 In the meantime, it is necessary to point out the different meanings of code respectively in the socially interactive level and the mathematical and mechanical level of machine languages. In the context of mathematical and mechanical level of machine languages, coding refers to the operation of codes in software. However, the term coding in this context of social interactions is a way of transmitting instructions between the addresser and the addressee.
} 
Overall, listing and navigation as ways of coding are operated as a selection and combination process of signs, such an operation lies in the relationship of sign, code and symbol. In addition, the diagram of the relationship of sign, code and symbol helps us to understand how the affects and volition emerge in the basic game play based upon the metalingual function.

\section{Signs, codes and symbols}

First of all, it is important to distinguish the works of sign, code and symbol in the building of the data structures of the Alphatown. Signs, in terms of Saussure (1959), stands in-between the signifier and the signified, and acquires value and meaning through having relationship between the signifier and the signified. If thinking about the reasoning process of Peirce, the sign as a representation of an object effectuates an interpretant as an ongoing and continuous process. In analogue with this, it can be considered that machine languages operate signs by a set of codes, whereby signs occur as the symbolic, the effects of themselves, and the set of code as an approach operates in the transition from signs to symbols. In relation to the building of data structures of the Alphatown, the set of codes is designated by game designer as the instructions of the game, while signs accumulate data and present attributes of things ${ }^{3}$ via mediations of lists and navigation tools, and are actualized as symbols. This process from sign to symbol operated by code reflects upon the metalingual function of machine languages.

The fact that signs enter into the symbolic is important because signs directly come into relationship with actions on the plane of the symbolic, and actions bring qualities of things to machines, which offers condition for the poetic function of machine languages to work within the metalingual functions. In the process of the work of signs, there are two tendencies that give conditions for signs to occur as symbols: the reification of signs and the actualization of symbols. To analyze the work of the reification of signs and the actualization of symbols, it is important to relate them to data materiality, which offers circumstances for the doubled process to occur.

Data materiality is manifested in the accumulation of data. Based on the mediations of listing and navigation, data in the architecture of the Alphatown is according to the operations of users' interests, hence the structure mediated by users shows the distribution of data. In the structure, the distribution of different streets, shops and apartments shows patterns of quantities of data added by users, and these quantities form sensible objects for users' experiences. For instance, the street with the name of Fugue Alley gives the sense of experiencing the street through a sense of music. The role of the sign here is as a process of recognition; it interacts with things and assigns value. The sign is "a process of selection, the selection of a set against a background... their selections change with circumstances" (Williams, 2016). It is worth noting that sometimes signs and symbols are easily mixed with each other, such as the name of the street can be a sign as well as symbolic,

3 These attributes of things are presented in names of streets, names and window images of shops and apartments. it is a sign when users sense the value of things, while it is symbolic when it denotes a thing after affecting users' experiences; the symbols are what have been actualized and are the result of signs, while the signs are processes of actualization.

Then what is the reification? If actualization is in the relationship with symbols, reification concerns the sign itself, the very process of selection. Regarding Jakobson's (1980) metalingual function, any verbal message in the selection and combination of its constituents involves a recourse to the given code. Selection and combination as elements of metalingual function are operated by code, which correlates with the structures of the virtual city of the Alphatown. For example, how the "style" of the street is presented is coded into the selection and combination of lists of shops along the streets; to add data onto the existing model, one needs to decode and recode symbols within the structures of the virtual city. To state these operations of code in selection and combination is to show that the process of signs allows sensations to assign value on things, specifically, one needs to recognize signs and experience the qualities of them in decoding and recoding. Regarding the issue of data materiality, as the symbol in one sense is the representation of the data substance, it contains certain quantities of data; in another sense, it stands for certain attributes of real things, for instance the symbol "Fugue" contains a certain amount of data added by users to this street structure, and also suggests the attribute of music to the amount of data. In relation to the process of recognizing signs, it appears that symbols are on the way to becoming signs in order to generate differentiated actions of data adding. Hence the reification of signs formulates and generates symbols that effectuate further actions, which in turn make symbols become signs in differentiating further actions of adding data.

\section{The emergence of the poetic function in the Alphatown}

Based on the above analysis, a doubled process of the reification of signs and the actualization of symbols articulates data materiality. Here, particular attention should be given to the differentiated actions of data adding on the plane of the symbolic, because they cause the new reification of signs and actualization of symbols. Actions in the case of the Alphatown refer to the users' acts in interacting with data structures, or more precisely, actions in this context mean intra-actions in the terms of Karen Barad (1996). The matter of data is a substance in its iterative intra-active becoming, "not a thing, but a doing, a congealing of agency" (Kleinman, 2012). Hence the reification of signs and the actualization of symbols can be encapsulated into a process of mattering operated by intra-actions. Such a formulation of matter processing is within the structures of media. The reasons are as below: on the one hand, the reification of signs and actualization of symbols belong to a kind of metalanguage operated by code, as well as a poetic function enacted in transmitting message, which I will explain later in the following part; on the other hand, intra-actions engender actions of mediating codes and messages in differentiating relations in structures. Hence, matter processing becomes inherent to structures of media. This level of matter processing offers the conditions for machine languages to generate differential relations of mediations; it demonstrates that the structures of media 
first of all are material, and then malleable and processual. In the meantime, the matter processing opens up space for volition as an agent to operate in the data structures of the Alphatown. The following part will analyze how matter processing offers the conditions for allowing the volition to arise and distribute.

The matter processing lies in the function of the poetic of machine languages, and to understand this, it is necessary to investigate how matter is distributed and formed in the reification of signs and the actualization of symbols. As illustrated above, the sign becomes a process of sensing and assigning value to things. This explanation corresponds to what Deleuze terms as a sign, an intense individuated sensation (Williams, 2005). Individual does not mean an individual person or subject, but refers to the circumstance of making parts and processes singular by differential agents. The process of signs on the one hand is operated by a code's selection and combination, on the other hand it brings the function of the poetic that focuses on the message. This formulation of message from addresser to addressee is instead manifested in the process of sensing enacted by the observers and effectuated by the actualizing symbols. Therefore, the poetic is the sensual, enactive function engendered by the selection and combination of coding in reifying signs and effectuating symbols. It is the poetic function that introduces the sensual and opens up space for intra-actions to operate on data structures and hence makes matter processing possible.

To summarize what has been outlined, the process of signs brings sensations in effectuating symbols, while symbols involve further actions triggered by the sensations to differentiate relations in structures, hence producing new selections and combinations of code in the new reification of signs. Based on this, two consequences on the plane of the symbolic condition the potential that media infrastructures store and transmit affects. The first consequence is that the symbolic implies the rearrangement of relations in structures. Because sensibility works with data materiality and signs are no longer constrained by signification between the signified and the signifier, there is free operatability regarding structuring data. The second consequence is the reciprocal determination in relations based on the rearrangement of relations in structures. This reciprocal determination in relations depends on the intra-actions in the poetic function of machine languages and is inscribed in the relations between the observer, data and media. To be specific, list, as the basic element of the architecture of the Alphatown, constitutes the rule of play: city streets, apartment blocks, the arrangements of shops and their interiors are designed based upon listing and one has to follow the orders of the lists to visit. However, the function of list is carried out in relation to the change of data structures and users' actions of mediation; for example, the navigation bar enables users to mobilize themselves from specific locations built on the list, offering the possibility of redistributing and restructuring data. On the other hand, the navigation bar isolates user operations and this sense of isolation is further mediated by lists, where users share their isolated experiences via communication tools. Such reciprocal determinations of complex relations between data, media and users allow the emergence and configuration of affects of boredom, being lost and strangeness in the structures of media.

\section{Conclusion}

In order to construct the argument that machine languages are structures of media, this paper first clarified what machine language is and then explained the different levels of machine language. Machine language is the operation of symbols. At its mathematical and mechanical level, its set of codes is executed directly by machines, while at its software and social interactive level, codes are selected and combined to communicate with the programming of the machines. There are two factors leading to thinking about machine languages as structures of media: signs of machine languages are analogue to signs of natural languages, and code and message in information and communication theory were introduced into linguistic theory to place languages in the studies of communication. With this context, code internalizes the commands and acts of machine languages, while the informing of commands and the effectuating of acts of machine languages make code communicative.

Such processes reflect the metalingual and poetic functions of machine languages in terms of Jakobson. To better understand these two major functions at an overall level of machine languages, a diagrammatic thought of machine languages based upon the thoughts of Peirce and Deleuze is required: At the mathematical and mechanical level of machine languages, because the operation of signs shows a speculative reasoning process involving hardware and software, whereby the machine simulates an object by operating signs hence effectuating acts through execution and implementation, this level of machine languages mainly act as metalingual function. At the social interactive level of machine languages, machine languages are actualized as material and sensual in the sense that social interactions bring about constructions on attributes of real things within software. ${ }^{4}$ This enacts different relations within realities, hence the process mainly focuses on the communication of messages that involve human and machine, i.e. the poetic function of machine languages. Here it is important to note that it is neither the mathematical and mechanical level only expressing the metalingual function, nor the socially interactive level only presenting the poetic function. Because of the interactive nature of software between human and machine, there needs to be a doubled process of coding: the algorithmic process of coding as well as the coding according to the rules of play that generates input for algorithmic coding. The latter process already shows a poetic function going through human activities and interior machines, hence the two major functions of the metalanguage and poetics co-function with each other under most circumstances.

Then the paper moved on to analyze the metalinguistic and poetic functions of machine languages in the case of the virtual city Alphatown. In the analysis of the media in the construction of data structures, listing and navigation as ways of coding are operated as a selection and combination process of signs. They distinguish different stages of the data structure construction, from the initial stage of data accumulation according to the designer's intention

\footnotetext{
4 For instance, the attribute of music is coded into the name of the street.
} 
and users' interest, to the generative stage of affect transmission. During these stages, the reification of signs and actualization of symbols mediate data structures: signs as processes are recognized and effectuate the generation of symbols, while further actions of mediations on symbols make symbols become signs and cause new reification of signs and actualization of symbols. Such a process of signs transiting to symbols operated by code is within the diagrammatic thought of machine languages, and reflects the metalingual function of machine language. Furthermore, under the circumstance of data materiality, the actions generating the reifications of signs and actualization of symbols lead to a matter processing, which shows the poetic function of machine language. These analyses indicate that machine languages become structures of media, while media are material and processual.

\section{Referências bibliográficas}

BARAD, K. (1996) "Meeting the Universe Halfway: Realism and Social Constructivism Without Contradiction", in Nelson, L. H. and Nelson, J. (eds.) Feminism, Science and the Philosophy of Science. Dordrecht: Kluwer Academic Publishers, pp. 161-194.

JAKOBSON, R. (1960) "Closing Statement: Linguistics and Poetics", in Sebeok, T. A. (ed.) Style in Language. Cambridge, MA: MIT Press, pp. 350-377.

JAKOBSON, R. (1980) "Metalanguage as a Linguistic Problem", in The Framework of Language. Michigan Studies in the Humanities, pp. 113-132.

KLEINMAN, A. (2012) "Intra-actions: Interview of Karen Barad by Adam Kleinmann", Mousse 34, pp. 76-81.

SAUSSURE, F. d. (1959) Balley, C. and Sechehaye, A. (eds.) Course in General Linguistics. New York: Philosophical Library.

VELLODI, K. (2014) "Diagrammatic Thought: Two Forms of Constructivism in C. S. Peirce and Gilles Deleuze", Parrhesia, 19, pp.79-95.

WILLIAMS, J. (2005) "Poststructuralism as Philosophy of Difference: Gilles Deleuze's Difference and Repetition", in Understanding Poststructuralism. Chesham, Bucks: Acumen.

WILLIAMS, J. (2016) "Process Semiology: A Simple Version", A Process Philosophy of Signs. Available from <http://www.jamesrwilliams.net/docs/Process-semiology-simply.pdf> (Accessed: 16 March, 2017). 